\title{
Diagnosis and molecular typing of rabies virus in samples stored in inadequate conditions
}

\author{
Fernando J Beltrán ${ }^{1}$, Federico Gury Dohmen ${ }^{1}$, Horacio Del Pietro ${ }^{3}$, Daniel M Cisterna ${ }^{2}$ \\ ${ }^{1}$ Area de Zoonosis Virales, Instituto de Zoonosis Luis Pasteur, Buenos Aires, Argentina \\ ${ }^{2}$ Servicio de Neurovirosis, INEI-ANLIS Dr. Carlos G. Malbrán, Buenos Aires, Argentina \\ ${ }^{3}$ Programa Nacional de rabia paresiante, Servicio Nacional de Sanidad y Calidad Agroalimentaria, Buenos Aires, \\ Argentina
}

\begin{abstract}
Introduction: The exposure of nervous tissue samples to high temperatures affects the sensitivity of rabies virus diagnostic tests, causing degradation of the viral structure. This study evaluated reverse transcriptase polymerase chain reaction (RT-PCR) for the diagnosis and molecular characterization of brain tissue samples in an advanced state of decomposition and poorly conserved viral isolates by comparing it with routine diagnostic tests.

Methodology: A panel of three canine brain samples exposed to controlled decomposition for 7, 15, 30, and 120 days were evaluated using fluorescence antibody test (FAT), mouse inoculation test (MIT), and RT-PCR. In addition, 14 isolates of rabies variants, representing the largest circulation in Argentina, preserved in inadequate cooling for six to eight years were analyzed. Molecular typing of strains was performed using a 159-nucleotide region corresponding to the nucleoprotein gene.

Results: The three samples analyzed were positive by RT-PCR at all the decomposition times evaluated, in contrast to results observed with FAT and MIT, which rapidly became negative. In addition, $100 \%$ of the inadequately preserved samples were characterized molecularly. The limit of detection of RT-PCR was $0.5 \mathrm{MICDL}_{50} / 0.03 \mathrm{~mL}$.

Conclusion: RT-PCR can be useful for rabies diagnosis and typing of putrefying samples or rabies isolates stored in inadequate conditions.
\end{abstract}

Key words: rabies; molecular typing; decomposed samples.

J Infect Dev Ctries 2014; 8(8):1016-1021.. doi:10.3855/jidc.4136

(Received 15 August 2013 - Accepted 09 Februadry 2014)

Copyright (C) 2014 Beltrán et al. This is an open-access article distributed under the Creative Commons Attribution License, which permits unrestricted use, distribution, and reproduction in any medium, provided the original work is properly cited.

\section{Introduction}

Rabies is a viral zoonosis of worldwide distribution that causes fatal encephalitis in humans and animals. This disease is caused by the rabies virus (RABV), belonging to the genus Lyssavirus, family Rahbdoviridae. RABV has an non-segmented negative-stranded RNA genome, enveloped by a double lipid membrane [1]. RABV is distributed in at least 150 countries, where more than 55,000 people die of rabies every year. Several species of mammals, especially those belonging to the order Carnivora and Quiroptera, are susceptible to RABV [2]. Dogs are considered to be the most important vector and are responsible for $95 \%$ of human rabies deaths [3]. In Argentina, the last case of human rabies transmitted by dogs was recorded in 2008 in the northern province of Jujuy [4]. In addition, in Latin America, there have been outbreaks of vampire bat bites and human cases transmitted by non-hematophagous species $[5,6]$.
In Argentina, the National Network of Regional Laboratories of Rabies performs routine diagnosis in brain tissue samples by the fluorescence antibody test (FAT) and mouse inoculation test (MIT). Furthermore, RABV isolates are sent to the National Reference Laboratory (Servicio Nacional de Calidad Agroalimentaria, SENASA) or to the National Coordinator Laboratory (Instituto de Zoonosis Luis Pasteur de Buenos Aires) to identify reservoir species by using a panel of monoclonal antibodies (antigenic characterization). Appropriate conservation and transportation of nervous tissue samples are critical factors for the precise interpretation of diagnostic tests. High temperatures, such as those recorded in rabiesendemic regions of northern Argentina, cause mild liquefaction to severe decomposition in submitted brain samples. These conditions could cause degradation of the virus structure and production of bacterial toxins that affect the sensitivity of rabies diagnostic tests [7]. If RABV isolates are not 
preserved at low temperatures $\left(-70^{\circ} \mathrm{C}\right.$ or lower), they rapidly lose their viability, which has caused the loss of many collections of RABV strains in laboratories that had inadequate infrastructure $[8,9]$.

Molecular biology techniques such as reverse transcriptase polymerase chain reaction (RT-PCR) are important diagnostic tools for the rabies virus [9-13]. They have also been used in several retrospective studies using samples stored under inadequate refrigeration for long periods of time [14]. PCR products can be sequenced and subjected to phylogenetic analysis, enabling accurate identification of the viral reservoir.

The aim of this study was to evaluate a RT-PCR assay for diagnosis and molecular characterization of rabies by comparing it with routine diagnostic tests using a panel consisting of decomposed brain samples under controlled conditions and RABV isolates stored at inadequate temperatures for several years.

\section{Methodology}

Samples and virus strains

To simulate samples in an advanced state of decomposition, three complete canine brains positive for rabies from Jujuy province stored at $-80^{\circ} \mathrm{C}$ (53703, 909-04, and 693-05) were placed in plastic collectors at room temperature $\left(20^{\circ} \mathrm{C} \pm 2^{\circ} \mathrm{C}\right)$ and protected from light. Aliquots from each sample were taken at 7, 15, 30, and 120 days.

The strains stored under refrigeration for long periods of time were studied using a group of 14 rabies isolates obtained from mouse brain samples from northern Argentina between 1999 and 2000. These strains were originally preserved in the regional laboratory at $-20^{\circ} \mathrm{C}$ for six to eight years and then sent to the Instituto de Zoonosis Luis Pasteur for further typing. However, these strains could not be characterized because the virus could not be amplified by MIT (Table 1).

In addition, in the molecular identification assay, a panel of 10 isolates representing the most common reservoir species harboring rabies in Argentina were used as controls: 552-97 (fox , antigenic variant 2, $\mathrm{AgV} 2$ ), 527-97-H (human, AgV3), 156-03 (Lasiurus spp., AgV6), 502-09 (Eptesicus furinalis, SP6), 12351209 and 524-10 (Histiotus montanus, SP6), 677-10 and 919-10 (Tadarida brasiliensis, AgV4), 634-12 (Myotis spp., SP13), and 882-08-H (human, AgV1). These isolates were previously characterized using a CDC panel of 19 monoclonal antibodies [15].

Fluorescence antibody and mouse inoculation tests (FAT and MIT)

All the aliquots obtained from decomposed artificially infected brains were tested by FAT. Conjugated monoclonal antibodies (Bio-Rad, MarneLa-Coquette, France) were used according to the manufacturer's instructions. MIT was performed according to the method of Koprowski, as previously described [16].

\section{RT-PCR and gene sequencing}

Viral RNA was extracted from samples using the QIAmp Viral RNA kit (Qiagen, Hilden, Germany), following the manufacturer's instructions. To detect rabies, reverse transcription and PCR amplification were carried out using the OneStep Kit RT-PCR (Qiagen, Germany) and primers 504 (5'TATACTCGAATCATGATGAATGGAGGTCGACT $\left.-3{ }^{\prime}\right)$ and 304 (5'-TTGACGAAGATCTTGCTCAT-3'),

Table 1. Molecular typing of RABV isolates stored at inadequate temperatures

\begin{tabular}{cccc}
\hline Strain/ Year & Species & City, Province & Reservoir \\
\hline $578-99$ & Dog & Puerto Rico, Misiones & Urban dog \\
$595-00$ & Bovine & Güemes, Misiones & Desmodus rotundus \\
$596-00$ & Insectivorous bat & Candelaria, Misiones & Eptesicus spp. \\
$605-00$ & Bovine & Ibarreta, Formosa & Desmodus rotundus \\
$608-00$ & Vampire & Laguna Yema, Formosa & Desmodus rotundus \\
$609-00$ & Vampire & Laguna Yema, Formosa & Desmodus rotundus \\
$615-01$ & Bovine & Ituzaingó, Corrientes & Desmodus rotundus \\
$620-01$ & Bovine & Villa Ocampo, Sta. Fe & Desmodus rotundus \\
$621-01$ & Bovine & Villa Ocampo, Sta. Fe & Desmodus rotundus \\
$626-01$ & NA & Villa Ocampo, Sta. Fe & Desmodus rotundus \\
$627-01$ & Human & San Luis del Palmar, Corrientes & Desmodus rotundus \\
$631-01$ & Bovine & Ituzaingó, Corrientes & Desmodus rotundus \\
$632-01$ & Bovine & Paraje Libertad, Corrientes & Desmodus rotundus \\
$660-01$ & Bovine & Apóstoles, Misiones & Desmodus rotundus \\
\hline NA & & &
\end{tabular}


as previously described [17]. Then, $5 \mu \mathrm{L}$ of the extracted RNA was added to $20 \mu \mathrm{L}$ of an RT-PCR mixture according to the manufacturer's instructions.

Amplification was performed using the following conditions: reverse transcription at $50^{\circ} \mathrm{C}$ for 30 minutes; denaturation at $95^{\circ} \mathrm{C}$ for 15 minutes; 40 cycles at $94^{\circ} \mathrm{C}$ for 1 minute, $50^{\circ} \mathrm{C}$ for 1 minute, and $72^{\circ} \mathrm{C}$ for 1 minute; and one final cycle at $72^{\circ} \mathrm{C}$ for 7 minutes. If necessary, to obtain an appropriate concentration of DNA for sequencing, a second round amplification was performed with $2 \mu \mathrm{L}$ of the firstround amplification. The PCR reaction was performed using Taq DNA-polymerase (Invitrogen, Carlsbad, CA, USA) to a final volume of $50 \mu \mathrm{L}$ with this profile: 5 minutes at $94^{\circ} \mathrm{C}$ followed by 40 cycles of 45 seconds at $94^{\circ} \mathrm{C}, 45$ seconds at $37^{\circ} \mathrm{C}$ and 45 seconds at $72^{\circ} \mathrm{C}$, and a final cycle of 10 minutes at $72^{\circ} \mathrm{C}$. The specific product of $249 \mathrm{bp}$ was analyzed using 2\% agarose Tris-acetate-EDTA gel electrophoresis. To carry out the complete assay procedure, distinct areas were established (clean reagents, extraction, and amplification rooms). A separate set of micropipettes with filtered tips was used in the different areas. For every run, a positive control (challenge virus standard, CVS) and a no-template control (sterile water) were included to detect possible cross-contamination between the specimens.

All the PCR products were purified with the QIAquick PCR Purification kit (Qiagen, Hilden, Germany) and sequenced with primer 304 using the BigDye Terminator v3.1 Cycle Sequencing Kit according to the manufacturer's protocol, using an Applied Biosystems 3500 series Genetic Analyzer. A 159-bp region of the nucleoprotein gene located between nucleotides 1318 and 1476 of the Pasteur Virus strain (M13215, GenBank) was analyzed. A phylogenetic tree was drawn using the neighborjoining method and Kimura parameters, with the MEGA 4.0 package [18]. Finally, 21 sequences representing rabies reservoirs in Argentina were obtained from GenBank and included for comparison purposes.
Figure 1. Analytical sensitivity of the RT-PCR assay. The analytical sensitivity of RT- PCR was determined using tenfold serial dilutions of the CVS virus stock starting from $10^{6.5}$ MICDL50/0.03 $\mathrm{mL}$ (lanes 2 to 9). Lane 1 and 11 correspond to the molecular weight marker (100-bp ladder), lane 10 to the negative control (water), and lane 8 to 0.5 $\mathrm{DL}_{50} / 0.03 \mathrm{~mL}$.

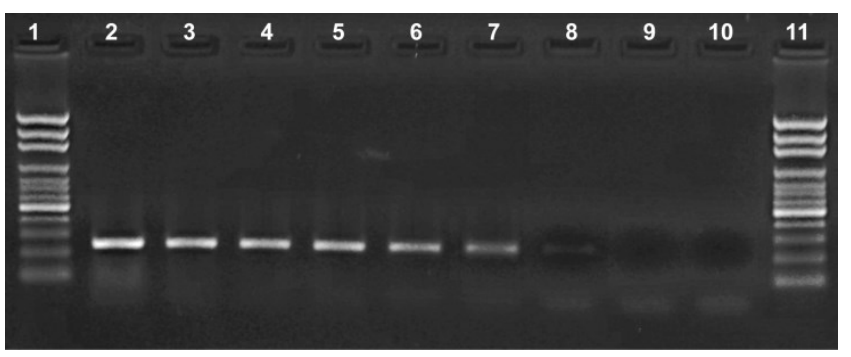

\section{Results}

The analytical sensitivity of RT-PCR was determined by using tenfold dilutions from the CVS rabies virus stock in suckling mouse brains, viral titer $10^{6.5}$ mouse intracerebral lethal doses $\left(\mathrm{MICDL}_{50}\right) / 0.03$ $\mathrm{mL})$. The limit of detection was $0.5 \mathrm{MICDL}_{50} / 0.03 \mathrm{~mL}$ (Figure 1).

Three positive dog brain tissue samples in decomposition conditions for different periods of times were analyzed using FAT, MIT, and RT-PCR. During the first seven days, all samples were positive by the three methods. However, the titers of FAT decreased markedly after day 15 , and then remained negative after day 30. Similarly, MIT became negative after day 15. In contrast, with RT-PCR, all samples were positive even after 120 days of exposure (Table 2). All the 14 strains stored in inadequate conditions were amplified by RT-PCR.

Phylogenetic analysis showed that the rabies sequences were divided into eight distinct groups with high bootstrap values corresponding of total viral reservoirs of each species tested (Figure 2). By this molecular approach, the most likely reservoir of rabies was identified from all aliquots obtained from the decomposing samples at 120 days and all the strains preserved in inadequate conditions (Table 2).

Table 2. Rabies diagnosis of samples in decomposition conditions

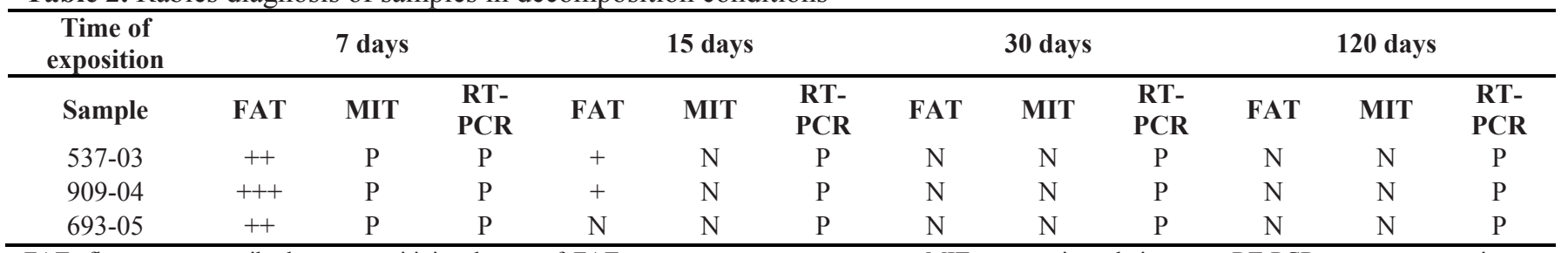

FAT: fluorescence antibody test; positivity degree of FAT:,,,,+++++++++++++++ ; MIT: mouse inoculation test; RT-PCR: reverse transcriptase polymerase chain reaction; $\mathrm{N}$ : negative; $\mathrm{P}$ : positive 


\section{Discussion}

The study of brain samples in different stages of decomposition presents a challenge to achieving an accurate diagnosis of rabies and to the recovery of improperly preserved sample collections. Factors affecting the sensitivity of the rabies diagnostic tests include the poor preservation of samples, the production of bacterial toxins, the initial viral load in the brains, and the reader's experience in fluorescence microscopy. According to the World Health Organization (WHO) recommendations, the RT-PCR technique should not be used for routine post-mortem diagnosis of rabies if brain tissue is available; the direct fluorescent antibody test should be used [3]. However, in decomposed samples, where traditional methods lose their sensitivity, RT-PCR becomes an important diagnostic tool $[7,10,11]$.

In this study, we evaluated the performance of RTPCR in detecting the rabies virus from putrefying canine brains or long-standing poorly maintained samples. We observed that, after the first week of exposure to room temperature, viral viability promptly diminished, whereas FAT results were positive after 15 days in spite of the loss of the anatomical limits of brain samples. Several authors have noted similar dynamics of both tests during exposure of canine brain samples to $25-29^{\circ} \mathrm{C}$, showing a better performance during 6-7 days for FAT and 48 hours for MIT $[7,19,20]$ Higher temperatures drastically reduce the chances of viral detection, and FAT is positive for 72 hours at $37^{\circ} \mathrm{C}[9]$.

Using RT-PCR, David et al. [11] found a positivity rate of $100 \%$, but only after 36 days of exposure in large animals at tropical temperatures. Under natural conditions of decomposition, the size of the brains of these species could encourage the viral preservation given its greater mass in contrast to smaller animals such as mice, where the rabies virus was detected until day 15 using a heminested PCR assay [19]. The RT-PCR has also proved to be useful in improperly preserved samples maintained in a glycerol solution for 5-6 years [21]. The detection rate declined from $88.9 \%$ to $65.3 \%$ in positive samples without storage medium stored at $-20^{\circ} \mathrm{C}$ or $-80^{\circ} \mathrm{C}$, for periods of up to 10 years [22]. Conversely, our assay was able to detect the rabies virus in all samples, even in those exposed for 120 days. Since rabies RNA could be highly degraded in putrefying brain samples, only small PCR fragments can be amplified. Therefore, our selection of primers directed to a short region of the nucleoprotein can be an advantage compared to other approaches that require higher
Figure 2. Phylogenetic tree of rabies samples stored in inadequate conditions. Phylogenetic tree constructed by using a 159-nt rabies virus (RABV) nucleoprotein sequence directly amplified from decomposed brain samples under controlled conditions and RABV isolates stored at inadequate temperatures. The phylogenetic tree was constructed using the neighbor-joining method. The robustness of the branching patterns was tested by 1,000 bootstrap pseudo-replications. Sequences obtained in this study are indicated as •: decomposed brain samples, $\boldsymbol{\nabla}$ : non-viable rabies isolates, $\mathbf{\square}$ : control panel. Reservoirs are indicated on the right. Nineteen RABV sequences from GenBank were used in the analysis. The scale bar indicates the number of nucleotide substitutions per site.

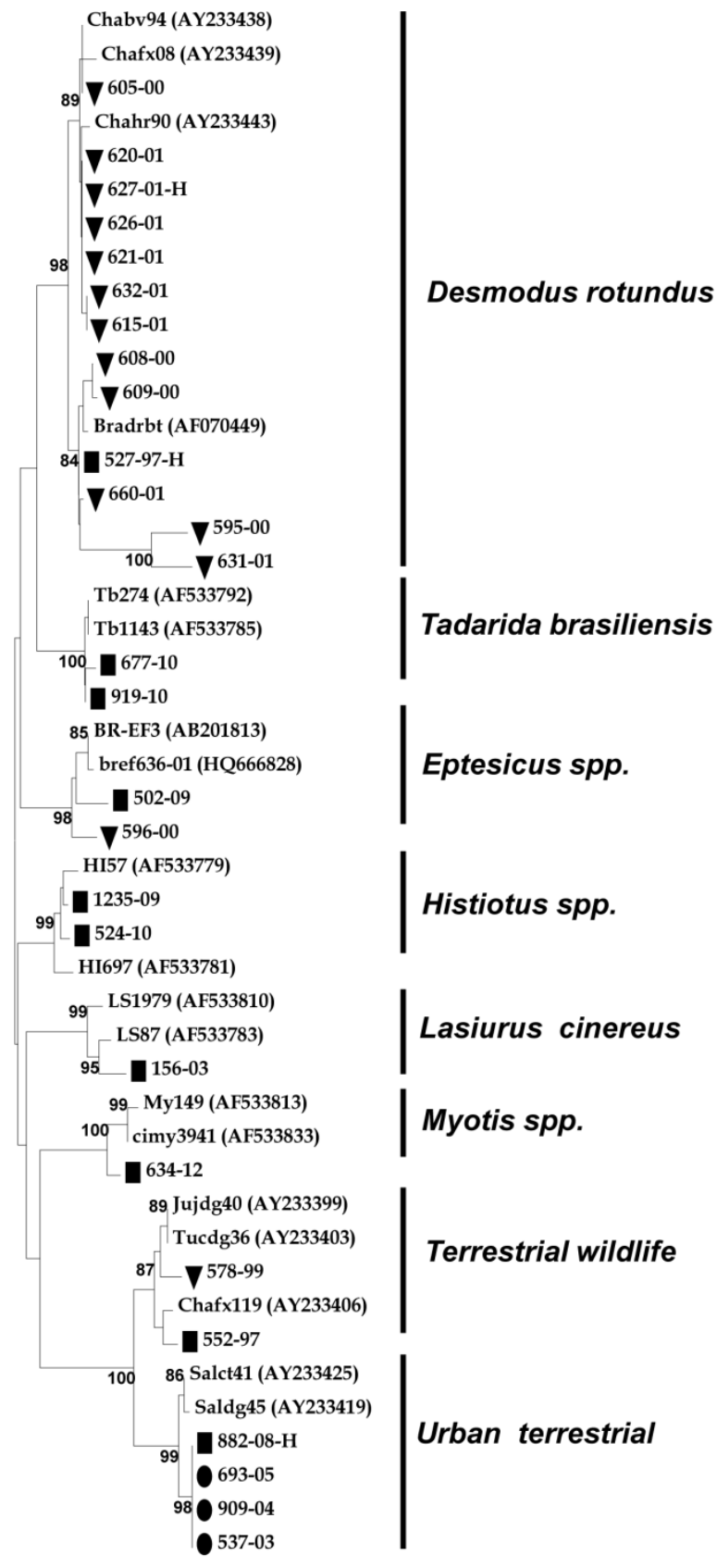

$\overline{0.05}$ 
structural integrity of viral RNA. Furthermore, the detection limit of $0.5 \mathrm{MICDL}_{50} / 0.03 \mathrm{~mL}$, as compared with that of other molecular techniques, is another advantage of PCR [23, 24].

In decomposed samples, in addition to detecting the rabies virus, the animal reservoir of the virus should be identified. In this study, we evaluated our method with a panel of 10 isolates of RABV corresponding to virus variants circulating in Argentina. The results showed that a 159-nt fragment of the viral nucleoprotein provided enough information to perform molecular typing directly on putrefying samples. The use of this tool allowed us to identify the reservoir of the 14 non-viable rabies isolates stored at $-20^{\circ} \mathrm{C}$ for six to eight years and to retrieve information from historical collections for retrospective epidemiological studies. Furthermore, the amplification and sequencing of the three samples of canine rabies outbreak collected during 2003-2005 revealed $100 \%$ homology with the human case that occurred in 2008 in Jujuy [4].

In our assay, strict quality control procedures were used to prevent carryover or crossover contamination. In addition, all positive samples were confirmed by nucleotide sequencing. However, the use of internal controls such as housekeeping genes or plasmids together with our method could avoid false negatives caused by inhibitors and contribute to improving the performance of this assay [25]. In the field of public health, taking into account the environmental conditions to which the sample was exposed, a negative result does not exclude the possibility of a false negative and we must thus consider the epidemiological information to administer appropriate treatment.

\section{Conclusion}

This study found that reverse transcriptase polymerase chain reaction can be very useful for rabies diagnosis and typing of putrefying samples or rabies isolates stored in inadequate conditions.

\section{Acknowledgements}

We thank all the professionals and non-professionals from the National Rabies Laboratories Network of the Ministry of Health of Argentina and Dra. Leda M. S. Kimura from PESAGRO-Rio, Brazil, for valuable discussions. This work was supported by Instituto de Zoonosis Luis Pasteur, Buenos Aires, Argentina.

\section{References}

1. Acha P, Szyfres B (2003) Rabia. In OPS, editor. Zoonosis y enfermedades transmisibles comunes al hombre y a los animales. Washington, DC: Publicación Científica y Técnica 580. 351-83.

2. Rupprecht C, Stohr K, Meredith C (2001). Rabies. In: Williams E, Barker IK, editors. Infectious Diseases of Wild Mammals. Ames: Iowa State University Press. 3-36.

3. World Health Organization (2013) WHO Expert Consultation on Rabies. Second report. World Health Organ Tech Rep Ser; 982:1-139 back cover. Epub 2013/09/28.

4. Gury-Dohmen F, Baspineiro B, Gury G, Martinez L, Miranda MR, Cisterna DM. [Diagnosis of a human rabies case in Jujuy, 2008]. Medicina (B Aires). 2009;69(6):643-6. Epub 2010/01/08. Diagnostico de un caso de rabia humana en Jujuy, 2008.

5. Favi M, de Mattos CA, Yung V, Chala E, Lopez LR, de Mattos CC. First case of human rabies in chile caused by an insectivorous bat virus variant. Emerging infectious diseases. 2002;8(1):79-81. Epub 2001/12/26.

6. Salmon-Mulanovich G, Vasquez A, Albujar C, Guevara C, Laguna-Torres VA, Salazar M, et al. Human rabies and rabies in vampire and nonvampire bat species, Southeastern Peru, 2007. Emerg Infect Dis. 2009;15(8):1308-10. Epub 2009/09/16.

7. Albas A, Ferrari CI, da Silva LH, Bernardi F, Ito FH. Influence of canine brain decomposition on laboratory diagnosis of rabies. Revista da Sociedade Brasileira de Medicina Tropical. 1999;32(1):19-22. Epub 1999/02/03.

8. Smith JS (1995) Rabies virus. In: Murray PR, Baron EJ, Pfaller MA, Tenover FC, Yolken RH, editors. Manual of Clinical Microbiology 6th ed. Washington, D.C: ASM Press. p. 1100.

9. Heaton PR, Johnstone P, McElhinney LM, Cowley R, O'Sullivan E, Whitby JE. Heminested PCR assay for detection of six genotypes of rabies and rabies-related viruses. Journal of clinical microbiology. 1997;35(11):2762-6. Epub 1997/11/14.

10. Araujo DB, Langoni H, Almeida MF, Megid J. Heminested reverse-transcriptase polymerase chain reaction (hnRT-PCR) as a tool for rabies virus detection in stored and decomposed samples. BMC Res Notes. 2008;1:17. Epub 2008/08/20.

11. David D, Yakobson B, Rotenberg D, Dveres N, Davidson I, Stram Y. Rabies virus detection by RT-PCR in decomposed naturally infected brains. Veterinary microbiology. 2002;87(2):111-8. Epub 2002/05/30.

12. Favoretto SR, Martorelli LF, Elkhoury MR, Zargo AM, Durigon EL. Rabies virus detection and phylogenetic studies in samples from an exhumed human. Clinical infectious diseases : an official publication of the Infectious Diseases Society of America. 2005;41(3):413-4. Epub 2005/07/12.

13. Soares RM, Bernardi F, Sakamoto SM, Heinemann MB, Cortez A, Alves LM, et al. A heminested polymerase chain reaction for the detection of Brazilian rabies isolates from vampire bats and herbivores. Memorias do Instituto Oswaldo Cruz. 2002;97(1):109-11. Epub 2002/05/07.

14. Dantas J, Kimura L, Ferreira M, Fialho A, Almeida M, Crégio $\mathrm{C}$, et al. Reverse transcription-polymerase chain reaction assay for rabies virus detection. Arq Bras Med Vet Zootec. 2004;56:398-400.

15. Smith JS, King AA. Monoclonal antibodies for the identification of rabies and in insectivorous bats of United States. Rev Infect Dis. 1998,10 (Suppl. 4).16. 
Koprowski H (1996) The mouse inoculation test. In: Merlin FX, Kaplan M, Koprowski H, editors. Laboratories techniques in rabies 4th ed. Geneva: World Health Organization; 80-7.

17. Orciari LA, Niezgoda M, Hanlon CA, Shaddock JH, Sanderlin DW, Yager PA, et al. Rapid clearance of SAG-2 rabies virus from dogs after oral vaccination. Vaccine. 2001;19(31):4511-8. Epub 2001/08/03.

18. Tamura K, Dudley J, Nei M, Kumar S. MEGA4: Molecular Evolutionary Genetics Analysis (MEGA) software version 4.0. Mol Biol Evol. 2007;24(8):1596-9.

19. Rojas Anaya E, Loza-Rubio E, Banda Ruiz VM, Hernandez Baumgarten E. Use of reverse transcription-polymerase chain reaction to determine the stability of rabies virus genome in brains kept at room temperature. J Vet Diagn Invest. 2006;18(1):98-101. Epub 2006/03/29.

20. Heaton PR, McElhinney LM, Lowings JP. Detection and identification of rabies and rabies-related viruses using rapidcycle PCR. Journal of virological methods. 1999;81(1-2):639. Epub 1999/09/17.

21. Biswal M, Ratho R, Mishra B. Usefulness of reverse transcriptase-polymerase chain reaction for detection of rabies RNA in archival samples. Jpn J Infect Dis. 2007;60(5):298-9. Epub 2007/09/21.

22. Lopes MC, Venditti LL, Queiroz LH. Comparison between RT-PCR and the mouse inoculation test for detection of rabies virus in samples kept for long periods under different conditions. J Virol Methods. 2010;164(1-2):19-23. Epub 2009/11/26.

23. Kang B, Oh J, Lee C, Park BK, Park Y, Hong K, et al. Evaluation of a rapid immunodiagnostic test kit for rabies virus. J Virol Methods. 2007;145(1):30-6. Epub 2007/07/14.

24. Yang DK, Shin EK, Oh YI, Lee KW, Lee CS, Kim SY, et al. Comparison of four diagnostic methods for detecting rabies viruses circulating in Korea. J Vet Sci. 2012;13(1):438.Muska A, Peck E, Palmer S (2007)

25. Muska A, Peck E, Palmer S (2007) Standards and controls: Concepts for preparation and use in real time PCR applications. In: Mackay IM, editor. Real Time PCR in microbiology. Norfolk, UK: Caister Academic Press. 101131.

\section{Corresponding author}

Daniel M. Cisterna

Servicio de Neurovirosis, INEI-ANLIS Dr. Carlos G. Malbrán

Buenos Aires, Argentina

Fax: 54-11-4302-5064 ext 213.

Phone: 54-11-4302-5064 ext 213.

Email: dcisterna@anlis.gov.ar

Conflict of interests: No conflict of interests is declared. 